\title{
Evolución de la identidad institucional en Andalucía
}

Enrique López-Marín; elm@ugr.es; Universidad de Granada, España

RESUMEN

A comienzos de 2020 la identidad visual de la Junta de Andalucía fue modificada sustancialmente, al ser reemplazado por el gobierno regional el símbolo identificador y el logotipo de la comunidad. El símbolo escogido, basado en la letra "A" como inicial de Andalucía, ha sido motivo de críticas desde diversos sectores de la población. Más allá de la pertinencia o lo acertado o no de la decisión, creemos que es interesante hacer una reflexión sobre los mecanismos de elección de la identidad -y sus consecuencias- en las instituciones públicas, y en particular de la que nos ocupa, la Junta de Andalucía.

PaLABRAs CLAVE

Andalucía; identidad corporativa; identidad institucional; logotipo; marca

The evolution of the institutional image in Andalusia

ABSTRACT

At the beginning of 2020 , the visual identity of the Junta de Andalucía was substantially modified, as the identifying symbol and the community logo were replaced by the regional government. The chosen symbol, based on the letter "A" as the initial of Andalusia, has been the subject of criticism from various sectors of the population. Beyond the relevance or the correctness or not of the decision, we believe that it is interesting to reflect on the mechanisms for choosing identity - and its consequences - in public institutions, and in particular the one at hand, the Junta of Andalusia. 


\section{Presentación}

A principios de 2020 el gobierno de la Junta de Andalucía decidió modificar los elementos identificadores de dicha institución, con el objetivo de poner de manifiesto el cambio político que se había producido en la comunidad. Estos cambios generaron opiniones diversas, contrarias unas veces, tanto por el contenido y la sustancia de los mismos como por el procedimiento para ejecutarlos. En ese debate, mantenido en la prensa regional y en el ámbito especializado y profesional, se pusieron de manifiesto ciertos errores en cuanto al origen de los símbolos vigentes. El interés del presente artículo es, por un lado, exponer una visión de conjunto de las distintas etapas que ha experimentado los elementos identitarios de la institución al recabar las fuentes históricas e icónicas de donde surgieron las formalizaciones gráficas así como una referencia a sus autores; y por otro, en la medida que un artículo lo permite, realizar un primer análisis de la eficacia y pertinencia de los sucesivos cambios y sus formalizaciones.

\section{Identidad corporativa e identidad institucional}

Mediante la denominación "identidad corporativa" nos referimos a aquellos elementos visuales, comunicacionales y organizativos que configuran el abanico de manifestaciones con las que una entidad privada o pública, comercial o institucional, utiliza para ser identificada frente a otras y mediante las cuales muestra sus intereses, valores, o actitudes a la sociedad. Estas aplicaciones son numerosas, pues pueden abarcar desde los elementos más básicos (anuncios, publicaciones, comunicados...) hasta los más complejos (señalética, interiorismo, productos industriales...). A su vez, estos aspectos también abarcarían a las formas directas de interactuar con sus clientes o usuarios - según proceda - o receptores en general, y afectarían a la atención directa, su cultura corporativa, los sentimientos o reacciones que provocan. En definitiva, influirán en cómo son percibidas estas entidades (Costa, 2003b, pp. 93-95), (Simões, Dibb y Fisk, 2005, p. 154), (Olins, 1979, p. 209). A estas manifestaciones que la entidad crea para ser reconocida le llamamos "identidad corporativa" y se suele plasmar en un manual de normas, y a su consecuencias, es decir, a cómo son recibidas e interpretadas, le llamamos "imagen corporativa" (García Garrido, 2018, pp. 106-112). Como en estas normas los aspectos visuales (logo, marca, color, tipografía...) ocupan un protagonismo evidente, se les suele acompañar el adjetivo "visual" en sus denominaciones, que a nuestro criterio es redundante, pues unas normas de identidad deben comprender todos los aspectos que la conforman, además de los exclusivamente visuales.

Así pues, la creación de un programa de identidad corporativa va más allá del diseño de un logotipo, pues deberá cubrir todas las manifestaciones que la empresa o institución presente a la sociedad, y hacerlo de una forma coherente, estableciendo y normalizando unos rasgos identificadores en una gran multiplicidad de manifestaciones sensibles con las que podemos reconocer una información, un producto, un servicio o un espacio. Que todos estos aspectos se articulen acertadamente es la labor más compleja y por ello la más profesional de dicho proyecto (García Garrido, 2018, p. 85).

F.H.K. Henrion define incluso tres entornos bien diferentes pero interrelacionados: el Diseño corporativo -la comunicación visual de una organización-; la Identidad Corporativa — que incluiría las acciones no estrictamente visuales, como las relaciones con la sociedad y el estilo de comunicación-; y las Comunicaciones Corporativas —que hace alusión a los medios para llegar a la sociedad- (Henrion, 1991, pp. 41-42). Frente a los que reducen esta actividad a la mera realización de un logotipo, las empresas gestionan valores que son intangibles pero que repercuten claramente en sus resultados, o la opinión pública puede transformarse según cómo se se proyecte la identificación de una institución u organismo público, de mayor o menor alcance.

La identidad corporativa es una disciplina relativamente nueva (Costa, 1987, p. 22), (González Solas, 2002, p. 39), (Tejeda, 2006, p 193), al tiempo que parte de una muy larga tradición (MüllerBrockmann, 1998, p. 9). Desde las marcas de las vasijas romanas, la heráldica medieval, los emblemas en el Renacimiento o las primeras marcas industriales, la necesidad de una identificación clara y favorable de un emisor ante su público siempre ha jugado un papel decisivo (Costa, 1987, pp. 3236) (Costa, 2004, pp. 29-52). Con la aparición de la sociedad de consumo, las empresas necesitaron diferenciar tanto los productos que fabrican como su propia reputación como organización -0 corporación-, para lo que se dotaron de instrumentos visuales que fuesen atractivos y que sobre todo, dejaran huella en sus destinatarios (Ogilvy, 2006, p. 24) (Tejeda, 2006, p 194). De la expresión "corporate identity" utilizada en el ámbito anglosajón se ha derivado la expresión identidad corporativa que utilizamos con frecuencia en el ámbito latino pero, en inglés, una "corporación" es una "empresa" sin ambigüedades, mientras que en español las expresiones "corporativo" o "corporativismo" puede tener connotaciones más amplias 
que las estrictamente referidas a una empresa o institución (Chaves, 1988, p. 18). En cualquier caso, acertada o no como expresión, su uso se ha extendido y es frecuente encontrarla referida a empresas e instituciones indistintamente, aunque el propio Chaves indica que en este último caso, según sus palabras, sería más conveniente utilizar la expresión "imagen o identidad institucional" (Chaves, 1988, pp. 18-19). Sobre la utilización de los términos "Identidad" o "Imagen", Joan Costa explica que "cuando todavía muchas empresas creen que la identidad es una cuestión simple de logotipos -o, todavía peor, creen que eso es la 'imagen'-, la noción de identidad corporativa se ha afirmado en tanto que la estrategia de la diferenciación por excelencia", y más delante continúa: 'La identidad corporativa es un 'sistema' de comunicación que se incorpora a la estrategia global de la empresa, y se extiende y está presente en todas sus manifestaciones, producciones, propiedades y actuaciones". Y concluye que: "gestionar la identidad es gestionar la imagen, pero no se puede invertir el proceso. La imagen necesita sustancia real: las cinco dimensiones de la identidad más la cultura. La imagen se gestiona, por tanto, indirectamente. Porque la identidad y la cultura, [...], son mensajes, cosas y relaciones que son emitidos y protagonizados por la empresa. $Y$ la imagen son percepciones y experiencias protagonizadas e interpretadas por los públicos" (Costa, 2003a). Pero creemos que no merece la pena extendernos más en esto.

\section{El caso andaluz: los orígenes de un símbolo} Como expone Eric Hobsbawm (2012, p. 20), el concepto de nación es mucho más reciente de lo que a menudo se cree, en la medida que las naciones que hoy conocemos se constituyeron hace no más de dos siglos, y ha sido necesarias "tradiciones inventadas" para que la nación-estado y sus fenómenos asociados — como los símbolos nacionales ${ }^{1}$

1. Sobre el concepto de símbolo, nos remitimos a la definición clásica de Peirce: "Un Símbolo es un signo que se refiere al Objeto que denota en virtud de una ley, usualmente una asociación de ideas generales que operan de modo tal que son la causa de que el Símbolo se interprete como referido a dicho Objeto" (Peirce, 1974, p. 30). Es decir, tiene un significado que parte de una convención o acuerdo general, y por lo tanto, es aceptado en ese contexto. Por otra parte, Malmberg los clasifica en: "símbolos ocasionales y convencionales o establecidos. Al primer grupo pertenece un retrato del rey o del jefe de Estado (que en efecto puede variar). A los últimos pertenecen todos los símbolos ofialmente sancionados por un grupo (un Estado, una comunidad, un movimiento, etc.). Ambos tipos pueden ser icónicos [...] y arbitrarios (la mayor parte de las banderas nacionales)" (Malmberg, 1977, p. 30). o las historias que las definen ${ }^{2}$ - tuvieran sentido y lugar en la mente o el corazón de sus habitantes. El sentir regionalista en Andalucía surge durante el siglo XIX, aunque hay autores como Blas Infante que lo remontan a épocas muy lejanas, y está íntimamente vinculado al movimiento cantonalista y federalista que se produjo en toda España durante la segunda mitad del siglo. Este movimiento dio lugar a la Constitución Federal de Antequera en 1883, de muy avanzados presupuestos políticos (Bernal, 1980, pp. 199-201). Posteriormente tiene lugar un regionalismo cultural que recupera tradiciones populares e identifica formas del "ser andaluz", con personajes como Machado Núñez y Sales y Ferrer, a los que le seguirán Machado Álvarez — padre de Antonio y Manuel-, Joaquín Guichot, o Hazañas, que serán los promotores de Ateneos, sociedades excursionistas o revistas que promueven los llamados Centros Andaluces, asociaciones que organizan el Congreso y Asamblea de Ronda (1913 y 1918) y la posterior Asamblea de Córdoba (1919).

Los Centros Andaluces fueron cerrados durante la Dictadura de Primo de Rivera, y con posterioridad se convierten en lo que se denominó Junta Liberalista de Andalucía, con el objetivo de promover la descentralización política de la región, en el intento de aunar fuerzas diversas que apoyaran la iniciativa incluso de signo político y cultural. La actitud de Blas Infante en este aspecto fue paradigmática, al entender que era un objetivo común de los andaluces y que superaba las barreras ideológicas. De esta forma, siempre se opuso a formar un grupo político específico de carácter nacionalista. Durante el periodo republicano se celebran reuniones entre municipios y diputaciones para preparar un proyecto de estatuto para la región, pero el golpe de estado de 1936 frustra el intento, y el nuevo régimen borra, incluso físicamente en la figura de Infante, cualquier vestigio del movimiento (Bernal,

2. "Muchas enseñas nacionales han retenido determinadas figuras cuya presencia multiplica el efecto de reconocimiento. Al respecto podemos distinguir dos categorías de representaciones sígnicas: una se caracteriza por hacer uso de signos abstractos o en parte simbólicos, como la cruz, el círculo, etc., entre los que de uso más más frecuente es la estrella. Ésta representa la noción de conjunto unificado de diferentes estados, como en el caso de Estados Unidos de América del Norte, donde los cincuenta y dos que los componen aparecen simbolizados por sendas estrellas, o bien es el componente del símbolo del Islam, que consiste en la reunión del signo falciforme de la Luna y de la estrella. En el siglo XX muchos estados socialistas se han apropiado de la estrella como signo distintivo. La segunda categoría de blasones se caracteriza por el recurso a representaciones realistas de las que se puede conservar fácilmente una poderosa impresión visual. [...] Que en cierto modo podemos considerar [...] integrantes de la Heráldica moderna, pese a que en el fondo encierran un carácter propiamente simbólico" (Frutiger, 1985, pp. 252-253). 


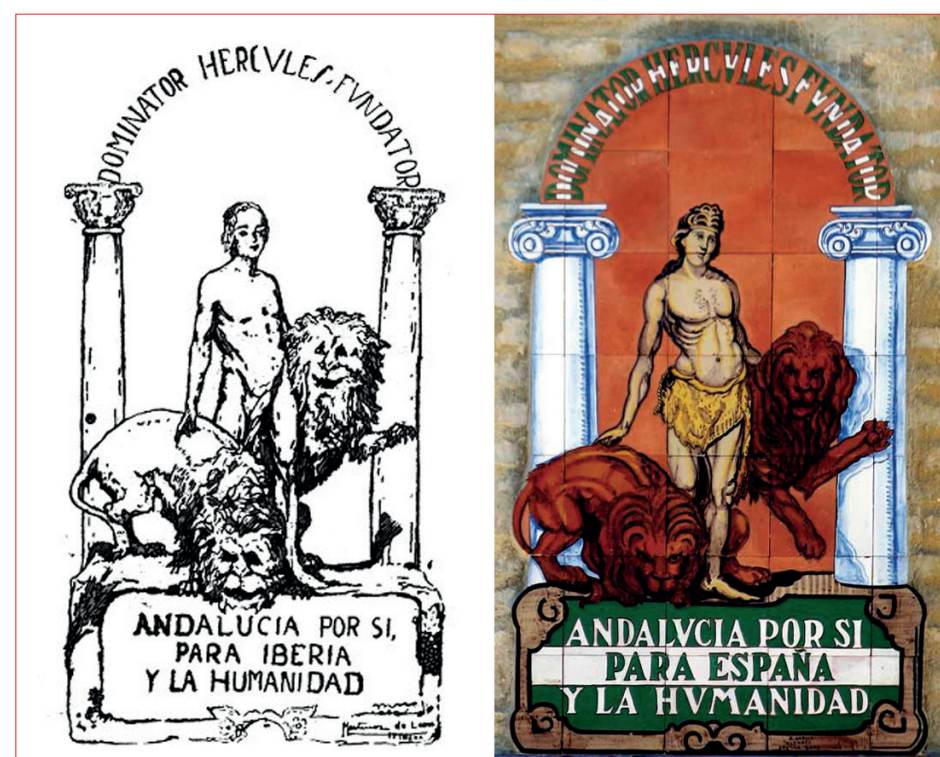

Figura 1. Dibujo de Andrés Martínez de León que representa la idea original de Blas Infante sobre el escudo y traslación de dicho dibujo al azulejo en la casa-museo de Blas Infante.
1980, pp. 200). En cualquier caso, la incidencia de un movimiento nacionalista siempre fue limitado socialmente, en la medida que se circunscribió a la pequeña burguesía, comerciantes e intelectuales. El rechazo de los grandes propietarios al movimiento regionalista existió desde el principio, pues estos siempre tuvieron una conexión estrecha con el Gobierno central y los poderes económicos nacionales. Por otro lado, el nacionalismo andaluz, aunque nunca promovió actitudes separatistas o radicales, sí destacó que el principal problema de Andalucía era el desigual reparto y uso de las tierras, lo que mantenía unas clases jornaleras muy empobrecidas en el ámbito rural. Este desigual reparto de la tierra se mantuvo en las propuestas del movimiento regenerador como prioritarias, estableciendo incluso conexiones con el anarquismo, muy presente entre las clases jornaleras. Frente a otras regiones con una burguesía industrial y comercial que respaldó a movimientos nacionalistas, el andaluz nunca gozó de grandes apoyos ni en estas capas sociales, ni tampoco en las clases trabajadoras -que desconfiaban de los nacionalismos (Hobsbawm, 2013, p. 149)—, preocupadas por el cambio de sus condiciones de vida y más cercanas al internacionalismo (González de Molina y Sevilla Guzmán, 1987, pp. 79-82).

En 1978, Andalucía consigue la preautonomía de la región, lo que permite constituir una entidad - la Junta de Andalucía- que facilitará el modelo de gestión descentralizado que empezaba a con- figurar lo que se conoce como "la España de las autonomías" tras la aprobación de la Constitución de 1977. Este organismo debía planear la forma de hacer efectiva dicha autonomía política y administrativa y, tras una etapa embrionaria donde empiezan a transferirse tanto del gobierno central como de las diputaciones las competencias básicas, Andalucía consigue con el referéndum de febrero de 1980 la autonomía regional plena y configurarse como una de las regiones que optaban por el abanico de competencias que habilita el artículo 151 de la Constitución española.

Sin experiencia de autogobierno, Andalucía emprendía una etapa donde todo estaba por hacer. El fin del periodo republicano a partir del golpe de 1936 impidió desarrollar instituciones que permitieran la descentralización administrativa. Los intentos de articular un nacionalismo regenerador en las primeras décadas del siglo a partir de los acuerdos y propuestas de la Junta Liberalista de Andalucía, la Asamblea Federalista de Antequera de 1883, la de Ronda de 1918 o la de Córdoba de 1919 habían quedado sobre el papel, lo que hizo que el nacionalismo o regionalismo andaluz se moviera en un ámbito teórico durante los primeros años de la instauración de la democracia española.

Frente a una nación, la española, donde se recuperan símbolos, banderas, lenguas, himnos y se plantean agravios históricos, en Andalucía no hay rasgos étnicos propios, ni lengua específica, -aunque siempre ha habido defensores de una habla andaluza como seña propia frente a las formas convenidas del castellano "correcto"-, o instituciones de gobierno históricas, el nacionalismo andaluz no encuentra un factor que pueda aducir y que la distinga de las demás comunidades, lo que hizo necesario la construcción de un relato que diera armazón a unas señas de identidad colectiva, y con ello la creación de una "comunidad imaginada" (Anderson, 1993) en la medida que buscamos unas referencias comunes con las que reconocernos. En cambio, si se le pregunta a un andaluz qué lo diferencia y particulariza, parece estar claro cuales son sus características o tópicos, incluso para autores alejados de los nacionalismos, como Ortega y Gasset (1942).

Sin otras referencias, los símbolos regionales (bandera o escudo) a los que se acude, son las propuestas de Blas Infante, teórico del andalucismo y figura destacada del mismo, y que habían sido aprobados por en la Asamblea de Ronda de 1918 (Ortiz de Lanzagorta, 1977, pp. 23-23), aunque ya en Ideal Andaluz (1915) Blas Infante lo había propuesto: "[...] hay que volver a levantar un templo al hércules Heleno, al divino héroe creador de la 
leyenda hesiódica, hijo de la fortaleza, de lo infatigable y de la consciencia del poder. Por esto, si yo pudiese elegir un escudo para Andalucía, señalaría sin vacilar el de la gloriosa Cádiz, con su divisa elocuente: "Dominator Hercules Fundator"' (Infante, 2010, p. 227).

Dejando a un lado el himno, que se aprobaría más tarde, estos símbolos consisten en la bandera verde, blanca y verde, y el escudo-emblema basado en el del municipio de Cádiz: la figura del Hércules mitológico acompañado de dos leones y flanqueados por las columnas que, según el geógrafo griego Heródoto, separaban el Mediterráneo del Atlántico en el Estrecho de Gibraltar. Este grupo lo cubre un arco con la bandera y donde reza la leyenda "Dominator Hércules Fundator", y en su base, una cartela, también con fondo verde y blanco, reproduce la leyenda "Andalucía, por sí, para España y la Humanidad”. Así pues, los símbolos aprobados por la Asamblea de Ronda de 1918 se convierten, tras la recuperación democrática, en los símbolos de la Comunidad, y pasan a ser oficiales y explícitos el 4 de enero de 1983 (Ley 3/1982, 1983).

Más allá de consideraciones de pertinencia heráldica, que motivaron la consiguiente polémica y que incluso se reflejó en la propia redacción de la Ley que los instaura, el escudo de Andalucía queda establecido a partir del propuesto por Blas Infante y se plasmó en el dibujo de Andrés Martínez de León, posteriormente convertido en el azulejo existente en la casa de Blas Infante - actual casa museo- de Coria del Río (García Garrido, 2017).

Este escudo de Andalucía se había aceptado tal y como fue propuesto por Infante, aunque Ortiz de Lanzagorta opinaba que el símbolo de la "granada", único símbolo de origen andaluz que existe en el escudo de España, podría haber sido la pieza que faltaba en el escudo andaluz para completar el recorrido histórico de la región (Ortiz de Lanzagorta, 1977, p. 25). Este elemento de difícil encaje hubiera hecho más complejo al escudo, en la medida que el mismo representa una composición casi escenográfica, y no responde a la estructura heráldica tradicional, donde diversos elementos, en escalas diversas, se articulan insertando significados y referencias.

Es necesario destacar que la denominación "escudo" se refiere al blasón, el escudo protector utilizado en la guerra como una protección y arma, que se convertirá en el elemento identificador de la nobleza. En cambio, un "emblema" es un grupo alegórico, con leyendas y significados. En este caso, el denominado escudo de Andalucía está más próximo al emblema, aunque no responda exactamente al sentido tradicional del mismo.
La inclusión de los leones junto con la figura de Hércules ha sido también discutida, pues su inserción reproduce tal cual al escudo de la ciudad de Cádiz, y éstos simbolizan la fuerza y el vigor a los que va asociado este animal. En cambio, es interesante la aportación del historiador Jesús Vergara acerca de los posibles vínculos entre este escudo/ emblema andalucista y el adoptado por el sindicato CNT en su congreso de 1918, que representa a Hércules venciendo al león de $\mathrm{Nemea}^{3}$, máxime si tenemos en cuenta la proximidad que manifestaron los andalucistas hacia el anarcosindicalismo español en la medida que este fue el representante mayoritario del campesinado andaluz.

\section{Las etapas de la identidad institucional}

Aunque de distinta duración, podemos establecer cuatro etapas en la identidad gráfica de la Junta de Andalucía:

1. Una etapa previa en la que, tras la redacción del Estatuto, se definen sus símbolos y donde la Administración autonómica los plasma en una propuesta visual. Se elabora pues una representación del escudo, acompañado del texto como logotipo "Junta de Andalucía", así como una versión abreviada. Este periodo previo abarca desde enero de 1983 hasta septiembre de 1985.

2. A partir de esta fecha se inicia una segunda etapa en la que se presenta el Programa de Identidad corporativa encargado al diseñador Alberto Corazón, que establece una versión sintetizada del escudo, una tipografía que denomina "alfabeto andaluz" para la configuración del logotipo y marcas asociadas a la institución, y le acompaña un breve desarrollo de aplicaciones generales y básicas.

3. Tras un periodo donde la institución se ha consolidado en la sociedad andaluza, en octubre de 1997 la Junta de Andalucía presenta una remodelación de su identidad, optando esta vez por encargar el diseño a una empresa sin trayectoria específica en esta actividad. A partir de la utilización del logotipo anterior, modificándolo e introduciendo un símbolo mucho más sintético, termina implantándose en innumerables soportes que utiliza o promueve la comunidad autónoma.

4. Por último, a finales de 2019 se conoce a través de la prensa que el nuevo gobierno autonómico tiene intención de modificar la identidad visual

3. Este emblema de la CNT está a su vez rodeado por una corona de laurel, así como lo estuvo el de Andalucía presente en el estrado de la Asamblea de Ronda de 1918, y que curiosamente, ha recuperado el actual presidente de la comunidad utilizando un pin de solapa con esta disposición. 


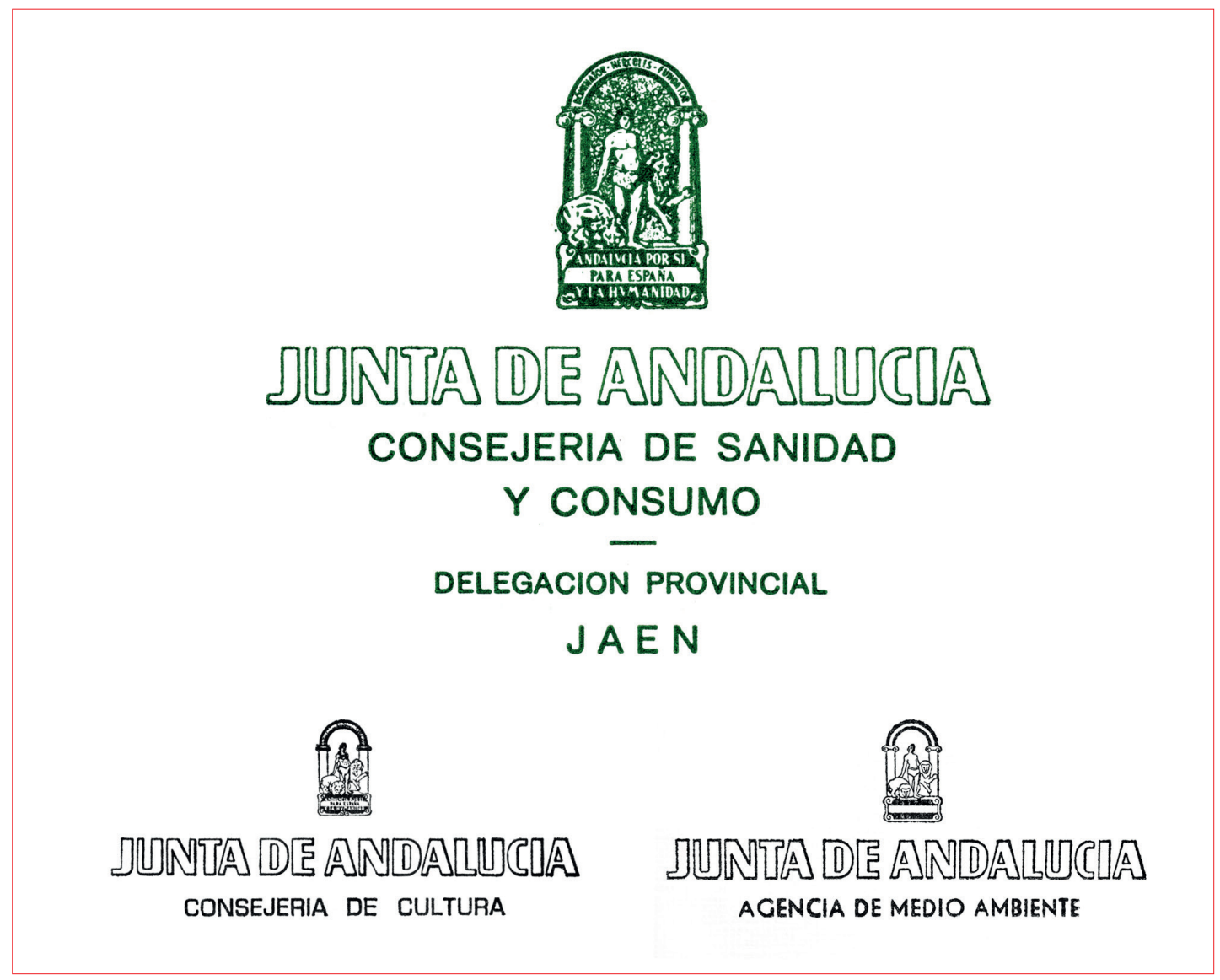

Figura 2. Distintos membretes utilizados en el periodo de 1982 a 1985.

de la Junta de Andalucía. La propuesta de partida se da a conocer en enero de 2020 y empieza a ser utilizado por la Administración andaluza sin tener elaborado un programa de identidad ni unas normas de aplicación definidas.

\section{Primera etapa (1983-1985)}

Los elementos identificadores de partida son de difícil reproducción en tamaños pequeños (tarjetas, membretes...) y en sistemas de señalización y rotulación. La reproducción impresa de tal amalgama de elementos, textos, detalles, se empastan y funden generando imágenes confusas e indistinguibles. Por otro lado, nada hay decidido en cuanto al texto o logotipo de la institución que lo utiliza: la Junta de Andalucía o al menos no se manifiesta en ninguna normativa publicada.

La primera propuesta de identidad es elaborada según tenemos noticia por el diseñador sevillano Félix Rivas a partir del escudo que se aprobó en la Asamblea de Ronda. La representación de la que se parte es el azulejo existente en la casa de Blas
Infante, y se realiza una traslación mimética del mismo, con un grafismo de línea (blanco y negro). Incluso podemos ver distintas versiones del emblema según la procedencia del impreso, unas con detalle y otras, más simples.

En cuanto al texto que forma el logotipo, se opta por una tipografía outline o de contorno, de formas muy cuadradas y en caja alta. Esta construcción básica —escudo o emblema junto con logotipose organiza en una disposición centrada. Le acompaña una versión reducida a la que se le denomina "logotipo de reproducciones simplificadas" (Decreto 211/1983, 1983), solución que se establece ante los problemas de reproducción a causa de la complejidad de los elementos identificadores, el reducido tamaño que se requiere (tarjetas, membretes de carta, etc.) y las características del medio de reproducción utilizado mayoritariamente en esta época para estos menesteres: la impresión en relieve o tipográfica. Este sistema provoca el desbordamiento de la tinta y el consiguiente empastado de la imagen; como también ocurre con los 


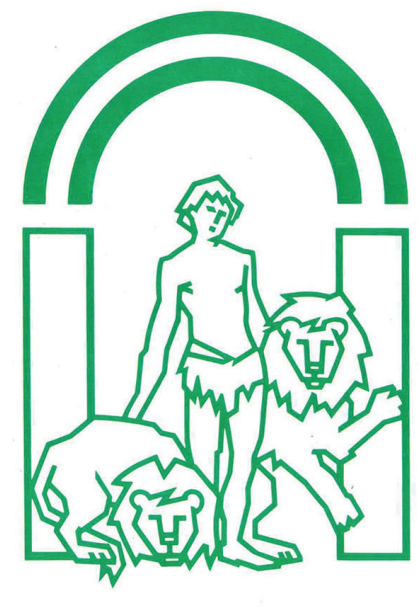

JUNTA DE ANDRLUCIA

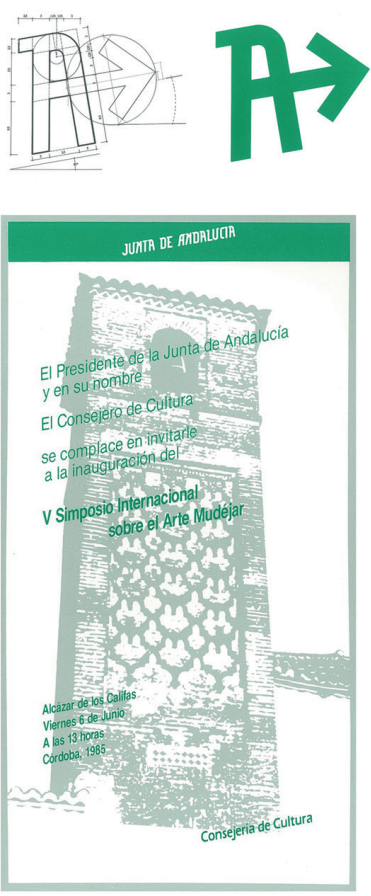

Figura 3. Elementos definidores del Manual de Identidad corporativa de la Junta de Andalucía de 1985. Signo y nombre, junto con ejemplos de disposición de los mismos en soportes.

sistemas de reproducción en oficinas, a través de las fotocopiadoras.

\section{Segunda etapa (1985-1997)}

En los años de la Transición, empresas de todo tipo renovaron su signos identificadores de forma radical para ser reconocibles. Tanto los organismos públicos como las entidades privadas en este proceso de renovación y cambio pugnaban por transmitir una imagen moderna y diferenciada totalmente nueva, y un ejemplo paradigmático fueron las entidades bancarias o las petroleras (claramente visibles en la identificación de las gasolineras).

Los ministerios buscaron diferenciarse y consolidarse como organismos con voluntad de servicio público en un estado democrático, opuestos a la distancia de los del régimen anterior; con soportes comunicacionales eficaces y de clara aceptación social. Con la expansión de actividades de las comunidades autónomas, se desarrollan competencias y ámbitos de actuación, pues al ser instituciones desconocidas por los ciudadanos, su desempeño en la sociedad debería quedar patente y visible.
En este contexto, la Junta de Andalucía adjudica la renovación de su identidad al diseñador madrileño Alberto Corazón, que realizaba encargos de prestigio para instituciones públicas especialmente: Ministerio de Obras Públicas, Renfe, Paradores, Centro Dramático Nacional, Tesoro Público, etc. El proyecto que acomete parte del emblema o escudo, pero realiza una síntesis del trazado del mismo, descargándolo de detalles innecesarios, y con un trazo regular y constante, se resuelven las formas de la figura de Hércules y los leones, al tiempo que se eliminan las leyendas y se simplifican las columnas. El resultado consigue una mejor reproducibilidad en dimensiones críticas por tamaño o visibilidad por distancia. Este "logotipo de reproducción simplificada" como denomina al emblema el decreto que lo establece, es aprobado en junio de 1985, con la intención de sustituir la versión simplificada de la etapa anterior. Posteriormente, en septiembre de este año, se presenta el Manual de Identidad Corporativa (Valenzuela, 1985). Constaba de un estuche con cinco cuadernillos breves agrupados por aplicaciones: nombre y signo, impresos, embalajes, publicaciones y señalización. En el mismo se defiende que este "manual es un 
elemento técnico, de trabajo, y no lo que se entiende como un elemento de imagen", reivindicando con ello el uso como "instrumento de trabajo que, aplicado a las necesidades funcionales de una comunidad como Andalucía, estructura el contenido comunicacional de todos los soportes institucionales" (Corazón, 1985).

Junto con la creación del emblema de nueva factura, al que los autores denominan "signo", se diseña un alfabeto tipográfico sólo en caja alta, en una versión normal y otra inclinada, para utilizar bajo una pauta ascendente. Con estos caracteres se compondrá el logotipo "Junta de Andalucía" para su uso general. Esta tipografía, a medio camino entre una fuente de palo seco y una egipcia o mecana, tiene un trazo constante que se mantiene en todo su trazado, tanto en los ascendentes, los trazos horizontales, como en los remates que algunos caracteres muestran. La intención del diseñador fue contar con una fuente que, dotada de una marcada personalidad, pudiera reproducirse en formatos pequeños en medios de impresión extremos (prensa, copiadoras...), así como rotularse fácilmente sin complicaciones.

En el proceso de creación, el equipo comprueba las posibilidades que el texto compuesto como logotipo ofrece al disponerlo en una progresión ascendente, transmitiendo con ello una acción de gobierno dinámica. Quizás fue, como apuntábamos antes, uno de las estrategias que las nuevas autonomías debían mostrar a sus ciudadanos. Para ello, adapta los caracteres a una versión cursiva se utilizará siempre en dicha disposición ascendente al $10 \%$ que nunca irá acompañada del signo o emblema. El uso de este se limita a la composición junto con la versión redonda del logotipo o nombre. La articulación y utilización posterior de este alfabeto queda abierta para componer nuevos "nombres" de organismos dependientes, como sucedió con el IARA (Instituto Andaluz de Reforma Agraria).

Para la reproducción del signo y el nombre o logotipo, la utilización del color se unifica al pantone 355, un verde medio que se aproxima al color de la bandera. Quedan eliminados pues, otras posibilidades de color que se habían utilizado en la etapa anterior.

Por otro lado, se plantean tipografías auxiliares para la entidades que forman la Junta. Las denominaciones de las consejerías se construyen en Eras Bold itálica condensada con la pauta de inclinación del 10\%, mientras que los textos auxiliares (dirección, teléfonos) se componen en Avant Garde Gothic estrechada y en el color gris pantone 446.

Este manual supuso un primer intento coherente de dotar a la comunidad andaluza de unos elemen- tos identificadores orientados a sus posibles aplicaciones, eficaces en su reproducción, y al mismo tiempo, y de un marcado carácter contemporáneo. $Y$ aunque su desarrollo fue reducido al quedar muchas posibilidades de aplicación sin articular, permitió un punto de partida que dejaba puertas abiertas a un posterior desarrollo y concreción de aplicaciones, pero esto habría necesitado un equipo bien formado en torno a la continuidad del mismo y la clara decisión de la Junta de acometerlas. En los últimos años del siglo, con una Junta de Andalucía con plenas competencias estatutarias desarrolladas, era manifiesta la necesidad de aplicaciones para múltiples soportes. La identidad creada en 1985 fue interpretada de formas diversas, algunas muy convencionales, como la disposición central de emblema o escudo y logotipo, con la sucesión de organismos menores en escala reducida. El resultado mostraba grupos de textos e imágenes enormemente complejos y de difícil lectura, que en nada contribuían a los objetivos de sencillez y cercanía propuestos en el manual original.

\section{Tercera etapa (1997-2020)}

Es así como en 1997 la Junta decide ampliar y renovar su identidad, introduciendo modificaciones en la construcción del nombre y signo, así como con el desarrollo de nuevas aplicaciones. La ocasión era oportuna, pero las soluciones que resultaron no contribuyeron a solucionar los problemas sino, a veces, a agravarlos. También el contexto era muy diferente: aún gobernando el mismo partido (PSOE), habían cambiado las caras en el gobierno andaluz; la comunidad autónoma gestionaba ahora grandes recursos y personal, las áreas de Educación y Sanidad estaban transferidas al completo; así como una parte importante de las inversiones en infraestructuras, obras públicas y vivienda; eran numerosas las publicaciones y extensas las actividades culturales; una intensa labor de gestión de espacios naturales, de la que Andalucía había sido pionera, incluso desarrollando una identidad específica para los Espacios Naturales; y se canalizaban numerosas ayudas desde la Comunidad Europea. La entidad que gestionaba la mayor cantidad de recursos de la comunidad necesitaba dotarse de una identidad apropiada a sus competencias y alcance en la sociedad.

$Y$ es desde una necesidad concreta, la señalización, que se originó un concurso para el diseño de la misma, y que terminó derivando en la renovación de la identidad visual de la Junta de Andalucía. Esto quedó de manifiesto al adjudicarse el contrato a una empresa especializada en el área de la señalética: RC Consultores, con sedes en Madrid y Sevilla. 


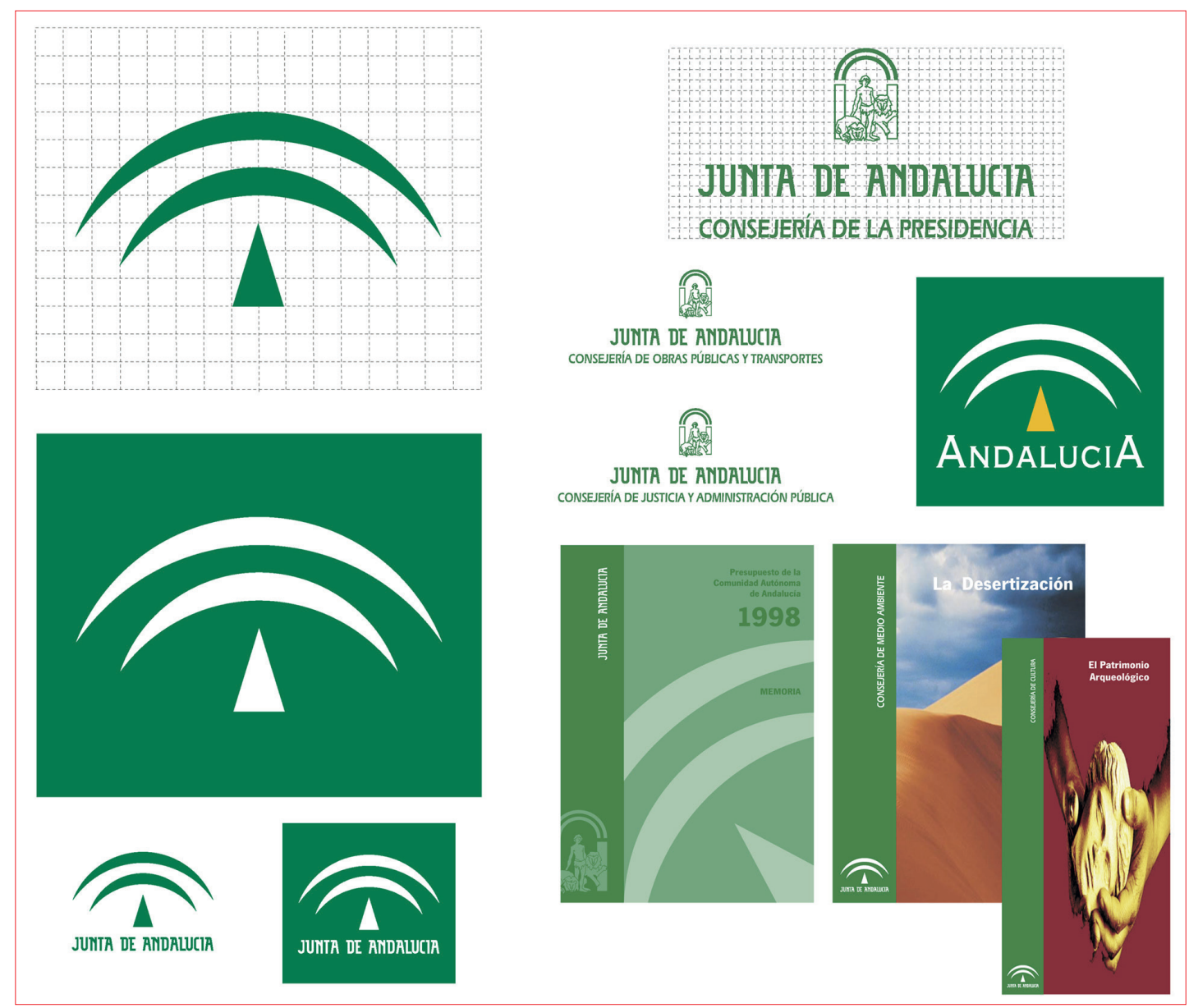

Figura 4. Signo implantado en 1997 y composiciones de utilización del mismo.

La transformación de la identidad de la Junta se hizo en base al anterior proyecto de Alberto Corazón: se utiliza la tipografía del nombre, el escudo para ciertos casos, el color (con retoques), pero se introduce además, un símbolo nuevo que monopolizará la mayor parte de las aplicaciones. Este símbolo pretende ser una abstracción del grupo formado por Hércules con los leones rodeados de dos columnas sobre las que gira, a modo de arco, la bandera. Así, se convierte en un triángulo isósceles al que cubre dos semicírculos con extremos afilados. Esta máxima abstracción, según el vicepresidente de la Junta, Gaspar Zarrías, "guarda las esencias de la identificación institucional, pero nos empuja a un futuro moderno en el que los símbolos sustituyen al lenguaje" (Lucio, 1997, p. 1); al tiempo que defiende que el ejecutivo "no podía permanecer impasible ante una sociedad que nos empuja hacia un futuro en el que los símbolos lo son todo" (Herencia, 1997, p. 19). Desde su presentación recibe un alud de críticas, tanto desde el Parlamento, donde se intentó paralizar su implantación, como desde un buen número de artistas y profesionales del diseño, calificado como "simple" y "desastre", y para los que el nuevo elemento identificador servía tanto para un envase de aceitunas — Juan Suárez-, como para una compañía de seguros o un banco, o incluso es definido como "el fantasma de la Madre Teresa de Calcuta"4_Rogelio López Cuenca-, (Molina, 1997, p. 11).

4. Teresa de Calcuta había fallecido poco antes y su singular aspecto e indumentaria estaba presente en todos. El símbolo recibió otros muchos calificativos, como "parapente" o "paraguas", como era conocido en las empresas de artes gráficas. También es de destacar el evidente parecido con el símbolo del Ministerio de Economía y Finanzas francés, implantado ese mismo año. Ver: https://fr.wikipedia.org/wiki/Ministère de |\%27Économie_et des_Finances_(France) [consulta febrero 2020]. 
El nuevo símbolo - al que se denomina "símbolo genérico"- se plantea como elemento funcional junto con el logotipo/nombre, para la mayor parte de las aplicaciones usuales, dejando el emblema/ escudo en un segundo nivel, pero sin dejar claro cuando prima el uso de uno u otro. El uso del escudo junto con el nombre en una disposición centrada se ratifica -algo que no estaba establecido en el Manual de 1985, donde se usaba la disposición horizontal, más interesante y dinámica-, al tiempo que se abandona la inclinación de $10^{\circ}$ grados para el logotipo. Poco a poco, el símbolo genérico irá inundando todos los soportes, relegándose el emblema a aplicaciones residuales, más allá de las estrictamente protocolarias, donde se sigue usando el escudo/emblema de 1983. El color se modifica, al sustituir el pantone 355 por el 356 (más oscuro), y se introduce el Pantone 617 como complementario y el negro (que ya era obvio, por otra parte). Se sigue utilizando la versión de la tipografía Eras estrechada al $80 \%$ para las consejerías, esta vez en caja alta, (lo que la hace de más difícil lectura, si ya no lo era antes), y se introduce una tipografía complementaria, la News Gothic para usos auxiliares y señalización.

Frente al protagonismo del nombre "Junta de Andalucía”, que había adquirido una fuerza de logotipo con el uso de la tipografía específica y su composición compacta y ascendente, el nuevo símbolo genérico lo oculta dentro de la construcción de los dos arcos y el triángulo, disminuyendo hasta lo ridículo una marca consolidada, de gran pregnancia y facilidad de reconocimiento visual. El conjunto, compacto y abstracto, sólo otorga sentido a los arcos, tan ambiguos como que podría tener cualquier significado por su nivel de abstracción. $Y$ en esta abstracción se desvanece el sentido iconográfico de representación y sus valores. Incluso la disposición del nombre se altera al invertir la letra "A" inicial de "Andalucía", restándole solidez al conjunto.

El resultado final es un manual más complejo, rígido hasta el encorsetamiento, al tiempo que ambiguo, al no definir los usos adecuados ni dejar claros los criterios de utilización de las distintas versiones vigentes de la identidad andaluza. Hasta el momento ha sido la identidad más prolongada en el tiempo; la más extendida, hasta lo invasivo; y quizás la más "transparente", en el sentido de pasar desapercibida; y la más indefinida, por la misma ambigüedad del signo. El símbolo que se terminó instaurando lo impregnó todo: desde los puentes en las autovías, las sábanas de los hospitales, los autobuses interurbanos y hasta las academias que impartían cursos homologados. Cualquier excusa era válida para dejar la marca de la institución. Sin distinción entre lo que es público o privado, importante o anecdótico, daba la impresión de vivir en un país monocorde.

Tras un recorrido de cuarenta años de gobierno del mismo partido, el PSOE, la presidencia de la Junta de Andalucía pasa al PP en diciembre de 2018. Aunque en el anterior periodo se habían sucedido varios presidentes y maneras diferentes de entender la gestión política, las competencias y atribuciones del gobierno regional eran numerosas y extensas y esto hacía que la identificación de la labor de la institución con partido que había gobernado ininterrumpidamente durante décadas era muy evidente. Es por lo que el nuevo gobierno salido de las elecciones de 2018 estima que hay que cambiar los elementos identificadores de la Junta $y$, como suele ocurrir, lo primero a lo que se recurre es a "cambiar los muebles", es decir, a cambiar la identidad visual y el logotipo.

\section{Cuarta etapa (2020-)}

A finales de 2019 se conoce la noticia de que el gobierno andaluz pretende cambiar el logotipo y la identificación visual de la institución autonómica. Se filtra en la prensa un boceto que deja perplejos a los profesionales de diseño, tanto por lo que ven como por el procedimiento, que no se conoce ni se hace público hasta que en enero de 2020 se presenta oficialmente. Una entidad de tal alcance, con casi 250.000 empleados directos y un presupuesto anual de más de treinta y seis mil millones de euros, cambia de logotipo a golpes de tuits, sin concurso público y con un presupuesto insignificante.

El nuevo diseño no elimina el emblema diseñado por Alberto Corazón, lo transforma simplificando los detalles y alterando las proporciones. Suprime la tipografía que hasta entonces había existido como elemento identificador, el "alfabeto andaluz" por una tipografía gratuita de uso libre, disponible en Google Fonts, la Noto Sans HK. También se sustituye el símbolo genérico por una "A" mayúscula, rotulada —no tipográfica-, en verde con dos tonos.

Estos cambios se dan a conocer de forma secundaria y casi anecdótica en una rueda de prensa por el consejero de presidencia, Elías Bendodo. En ningún momento se organiza una presentación oficial, sino que simplemente, este nuevo símbolo está presente en dicha aparición pública y el consejero explica brevemente las circunstancias de este cambio a las preguntas de los periodistas: es un contrato menor, con un coste de $14.500 €$ y la implantación de los nuevos elementos identificadores no supondrá un gasto adicional, pues 


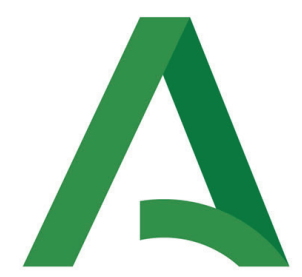

\section{Junta de Andalucía}

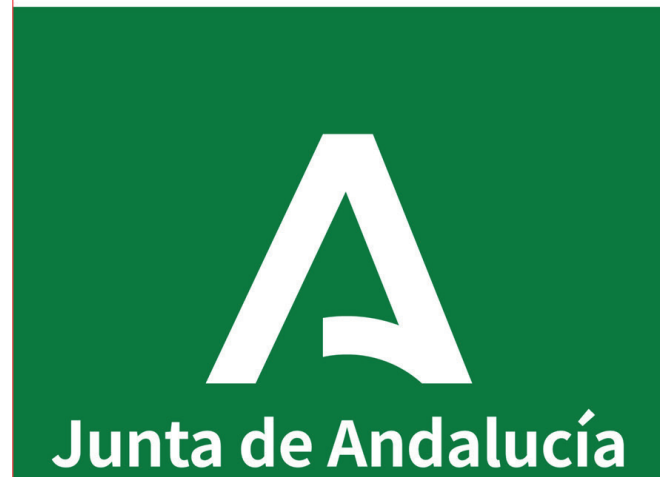

se aplicará a medida que sean necesarios fabricar nuevos soportes.

Los comentarios y críticas en redes sociales y en la prensa fueron inmediatos, desde la crítica por la Asociación Andaluza de Diseñadores por la falta de transparencia en la contratación, pues no existió concurso público, y lo interesante que hubiese sido una "llamada a proyecto", habitual en estos casos. Incluso por los partidos del Parlamento, ante la ausencia de argumentación en la decisión tomada, el porqué tirar por tierra una identificación ya consolidada de la institución; o las acusaciones de plagio en el nuevo símbolo que, tras su divulgación en las redes sociales, producen, cuanto menos, sonrojo (ABC Andalucía, 2020). La empresa destinataria del encargo es la productora audiovisual Happy Ending TV, que hasta la fecha, no mostraba ningún curriculum en su web en relación a este tipo de encargos. La creación de esta identidad es subcontratada al diseñador catalán Juan Carlos Patrón.
En cualquier caso, la cuestión que nos interesa estudiar es más técnica que política, pues el origen de este cambio es evidentemente la urgencia del nuevo ejecutivo en marcar distancias "visuales" con la etapa anterior. La anterior identidad de 1997 no había supuesto una ruptura radical, en la medida que, con modificaciones, conservaba la tipografía y el emblema de la versión de 1985 para algunos usos, pero sin definir con precisión; al tiempo que introdujo el nuevo símbolo genérico que se implantó de forma extensa. El nuevo símbolo de partida y principal argumento de este último cambio, la sustitución del símbolo genérico existente (arcos y triángulo) por una " $\mathrm{A}$ " abierta, es defendida por su autor con el siguiente argumento: "no hay nada que mejor identifique a alguien que su propia inicial, que está por encima de cualquier otra visión o interpretación, la A de todos los andaluces, la A de Andalucía", pues es "más actualizada, más sintética, más geométrica, 
que a nivel de reproducción técnica diera facilidades [...] fácilmente reconocible" (El Confidencial, 2020). Ni que decir tiene que con " $A$ " comienzan los nombres de otras regiones como Asturias o Aragón (que ya la usó en su emblema durante la lla República) y unas cuantas provincias españolas, por no seguir con Andorra, Albania y un largo etcétera. Sobre lo sintética o geométrica que puede ser cualquier "A" mayúscula, no creo que el nuevo símbolo haya añadido nada nuevo a lo ya conocido. Sobre las posibilidades de reproducción técnica, todavía está por explicar como se reproducen sobre señalización dos tonos muy similares de verde de los que consta dicho símbolo, y sobre la facilidad de reconocimiento, quizás le sea más fácil a un consumidor de Aquarius o de cualquier producto de Adobe Inc. (Morillo, 2020).

La necesidad de síntesis formal, de sencillez no está reñida con la cualidad de ser reconocible, con su facilidad visual, que no es atributo único de un concepto inicial, sino también de cómo está dispuesto el mismo para ser reproducido. El signo al que se recurre es básico, demasiado genérico y aséptico, sin trasfondo que lo justifique y sin ninguna alusión -a excepción del color verde- - a los elementos identificadores asimilados por los ciudadanos andaluces, un signo sin legado, sin historia (algo que en parte también le ocurría al anterior símbolo). La necesaria asociación de un símbolo con una idea debe construirse con el tiempo pero también debe sintetizar claramente el sentido que se quiere trasmitir, y debe estar bien fundado, ser reconocible por ser "único" en el entorno, y destacar sobre el resto. Poco de esto ocurre en el proyecto resultante.

Por otro lado, la tipografía a la que se recurre efectivamente va en sintonía con el símbolo: una tipografía global, que no tiene un valor de distinción que la haga reconocible frente a otras muchas similares. Con la composición tipográfica pueden transmitirse muchos más contenidos que el texto explícito, y por otro lado, el diseño tipográfico es quizás uno de los elementos que mejor definen una cultura, un país e incluso una época histórica.

La decisión de dar a conocer el símbolo sin un manual de diseño con aplicaciones claramente pensadas y contrastadas sólo se explica por la urgencia con las que fue concebido el proyecto. Las consecuencias, al día de hoy, son evidentes: membretes de consejerías hasta de seis líneas de información textual, composiciones no definidas (horizontal, vertical...), señalización donde se ha trasplantado el nuevo símbolo donde estaba el anterior, y un largo etcétera.

\section{A modo de conclusión}

En los cuarenta años transcurridos desde la implantación de la Junta de Andalucía, la institución ha tenido cuatro sistemas de identidad gráfica, visual o corporativa, de mayor o mejor alcance y desarrollo. Desde el primer proyecto embrionario, que trasladaba los bocetos y las imágenes que el andalucismo histórico había planteado como originales, el proyecto de 1985 de Alberto Corazón establece una base sólida para que una comunidad autónoma como la andaluza sea reconocida con unos símbolos definidos y articulados en base a su emblema-escudo y una tipografía realizada ex-profeso para este fin. Dentro de un programa breve pero coherentemente planteado, se pueden reconocer unos elementos identificadores acordes al momento y a las necesidades de comunicación. En 1997 se amplía las aplicaciones del anterior manual, pero introduce un símbolo nuevo (arcos y triángulo) que terminará convirtiéndose en el elemento identificador exclusivo de la Junta de Andalucía, por encima de logotipo (texto) e incluso del emblema-escudo. Éste manifiesta una evidente abstracción, escaso valor sígnico y de compleja reproducción, pero la política de la Junta de Andalucía, más allá de buscar una correcta implantación, lo exprime hasta hacerlo aparecer en todos los soportes con alguna relación con la institución. Este símbolo será reemplazado por el nuevo, la " $\mathrm{A}$ " partida que el nuevo ejecutivo presenta a principios de 2020. Este cambio hubiera sido una oportunidad para resolver los problemas históricos de la identidad andaluza:

1. El cometido de la identidad en un organismo de gobierno es la de facilitar la comunicación entre los ciudadanos y la institución. Andalucía siempre ha carecido de elementos definidores claros, por ello, hubiese sido necesaria una concreción clara de cuales son nuestros símbolos sin asociarlos a ninguna opción política.

2. A nuestro modo de ver, el gran problema de la identidad de la Junta de Andalucía es su desarrollo, articulación y aplicación. Pero sobre todo, la falta de un criterio de implantación coherente, de control sobre su propia identidad. Salvo la identidad de 1985, que establece unas bases coherentes en base a un logotipo o nombre de construcción tipográfica con un valor intrínseco, los otros desarrollos no han hecho más que complicar, recargar o podar lo que ya existía.

3. El resultado no debe evaluarse por opiniones relativas al gusto general, sino por una comprensión clara de que lo que vemos, además de tener sentido y aportar información, por enlazar con unas señas culturales y patrimoniales, 
además de ser un revulsivo identificador claro y potente.

4. Resolver el gran problema de la señalética de la institución, su rotulación y sus soportes, autopistas, entidades externas.

5. La tipografía es seña de identidad de una comunidad. Existe en las manifestaciones de la Junta un gran descuido en esta materia, donde no se ha valorado lo que la tipografía puede aportar y transmitir.

6. El problema del cromatismo, el color verde del nuevo símbolo con diversos tonos dificulta el uso de una versión de marca monocroma, imprescindible en ciertas aplicaciones.

7. Otro problema es la complejidad institucional que genera una entidad del alcance y la envergadura de la Junta de Andalucía. Un membrete donde en un solo bloque de 4 ó $5 \mathrm{~cm}^{2}$ aparezcan símbolo, nombre de la institución, consejería, dirección general y a veces, algo más, es realmente farragoso. Resolver los problemas comunicativos de la larga cadena de instituciones asociadas a una acción de gobierno: empresas públicas, consejerías, entes de diverso tipo, entidades externas a la administración, etc. Para ello hay que tomar decisiones estratégicas de qué es lo conveniente en la comunicación de la Junta de Andalucía, si primar la institución o buscar vías de personalización de sus organismos. Pero esto es una decisión compleja que va más allá de el logotipo, o mejor dicho, se debe tomar antes de cambiarlo.

8. Todas las versiones de la identidad andaluza fueron encargadas a empresas o profesionales, o bien ajenos a la profesión, o a diseñadores ajenos a la comunidad, si exceptuamos la breve de 1983 y que realmente no fue un desarrollo corporativo.

9. Una identidad visual debe abarcar diversos aspectos, y en una institución que representa una región con tan extenso bagaje cultural, se ignora al mismo con intervenciones de este tipo. En cierta forma, denota lo que ha sido la práctica de la comunidad en cuanto al conocimiento de su tradición iconográfica, y lo demostraron especialmente estas dos últimas propuestas.

10.En los últimos años, jóvenes profesionales han surgido en Andalucía demostrando un alto nivel como diseñadores y tipógrafos, y la Junta de Andalucía habría tenido una magnífica oportunidad para realizar un proyecto de excelencia en esta materia. 


\section{Referencias bibliográficas}

Anderson, B. (1993). Comunidades imaginadas. Reflexiones sobre el origen y la difusión del nacionalismo. México: Fondo de Cultura Económica.

Bernal, A.M. (1980). La Andalucía contemporánea. En VV.AA. Los andaluces (pp. 189-221). Madrid, España: Istmo.

ChAVES, N. (1988) La imagen corporativa. Teoría y metodología de la identificación institucional. Barcelona, España: Gustavo Gili.

Corazón, A. et al. (1985). Programa de Identidad Corporativa. Junta de Andalucía. Sevilla, España: Marín y Asociados.

CostA, J. (1987). Imagen Global. Evolución del Diseño de Identidad. Barcelona, España: Ediciones CEAC.

-, (2003a). Creación de la Imagen Corporativa. El paradigma del siglo XXI. En Razón y Palabra, Número 34, año 8, agosto-septiembre 2003. Recuperado de http://www.razonypalabra.org. $\mathrm{mx} /$ anteriores/n34/jcosta.html [consulta enero 2021].

—, (2003b). Diseñar para los ojos. La Paz, Bolivia: Grupo Editorial Design.

-, (2004). La imagen de marca. Un fenómeno social. Barcelona, España: Paidós Ibérica.

Decreto 211/1983, de 19 de Octubre, por el que se regula el logotipo de reproducción simplificado del Escudo de Andalucía para uso oficial. Boletín Oficial de la Junta de Andalucía, Sevilla, 8 de noviembre de 1983. BOJA n 89. Recuperado el 24 de mayo de 2020 de: https://www. juntadeandalucia.es/boja/1983/89/d2.pdf

Frutiger, A. (1981). Signos, símbolos, marcas, señales. Barcelona, España: Gustavo Gili.

García Garrido, S. (2017). Centenario de la definición del escudo de Andalucía. En Anuario 2017 de la Real Academia de Bellas Artes de San Telmo, Málaga. Segunda época, 145-158. Recuperado de https://www.realacademiasantelmo.org/centenario-de-la-definicion-del-escudo-de-andalucia/ [consulta abril 2020].

-, (2018). Diseño de comunicación corporativa: marca y diseño estratégico. Madrid, España: Experimenta Libros.

GonzÁlez Solas, J. (2002). Identidad Visual Corporativa. Madrid, España: Síntesis.

HeNRION, F.H.K. (1991). La imagen corporativa. En Cees de Jong (Ed.), Manual de Imagen corporativa (pp. 41-47). Barcelona, España: Gustavo Gili.

HeRenciA, J.A. (16 de octubre de 1997). Zarrías defiende la nueva imagen de la Junta como apuesta de futuro. El Correo de Andalucía, p. 19.
Hobsbawm, E., Ranger, T. (2012). La invención de la tradición. Barcelona, España: Planeta.

Hobsbawm, E. (2013). Naciones y nacionalismo desde 1780. Barcelona, España: Crítica Booket.

Infante Pérez, B. (2010). Ideal Andaluz. Varios estudios acerca del renacimiento de Andalucía. Sevilla, España: Centro de Estudios Andaluces.

Ley 3/1982, de 21 de Diciembre, sobre el Himno y el Escudo de Andalucía. Boletín Oficial de la Junta de Andalucía, Sevilla, 4 de enero de 1983. BOJA $n^{\circ}$ 1. Recuperado el 24 de mayo de 2020 de: https://www.juntadeandalucia.es/ boja/1983/1/d2.pdf

LucIo, L. (16 de octubre de 1997). PP e IU acusan al gobierno de apropiarse de la marca 'Junta de Andalucía' en el nuevo logo. El País Andalucía, p. 1.

Malmberg, B. (1977). Teoría de los signos. Introducción a la problemática de los signos y los símbolos. México DF, México: Siglo XXI editores.

Moguer, M. (2020, 1 de febrero). El nuevo logo de la Junta de Andalucía: mucha broma y varias plantillas «calcadas». ABC Andalucía. Recuperado de https://sevilla.abc.es/andalucia/sevinuevo-logo-junta-andalucia-mucha-broma-yvarias-plantillas-calcadas-202002011323_noticia.html [consulta junio 2020].

MolinA, M. (17 de octubre de 1997). Diseñadores y artistas andaluces califican el nuevo logo de la Junta de "simple" y "desastre". El País Andalucía, p. 11.

Morillo, I. (2020, 1 de febrero). Tras el logo de la Junta: un diseñador catalán y una productora 'pata negra'. El Confidencial. Recuperado de https://www.elconfidencial.com/espana/andalucia/2020-02-01/tras-el-logo-de-la-juntaun-disenador-catalan-y-una-productora-patanegra_2437336/ [consulta junio 2020].

Müller-Brockmann, J. (1998). Historia de la comunicación visual. Barcelona, España: Gustavo Gili.

OGILVY, D. (2006). La imagen de marca. En: Bassat, L. El libro rojo de las marcas (pp. 21-26). Barcelona, España: Debolsillo.

OLINS, W. (1979). Corporate identity. The myth and the reality. Journal of the Royal Society of Arts, 127(5272), 208-223. Retrieved January 28, 2021, from http://www.jstor.org/stable/41372923.

Ortega y Gasset, J. (1942). Teoría de Andalucía y otros ensayos. Madrid, España: Revista de Occidente. 
Ortiz de Lanzagorta, J. L. (1977). Símbolos de Andalucía. Un nombre, una bandera, un grito, un estatuto. Écija, España: Ed. Astigitana.

Peirce, Ch. S. (1974). La ciencia de la Semiótica. Buenos Aires, Argentina: Nueva Visión.

SımõES, C., Dibb, S., Fisk, R.P. (2005). Managing corporate identity: An internal perspective. JAMS 33, pp. 153-168. https://doi. org/10.1177/0092070304268920.

TEJeDA, J. G. (2006). Diccionario crítico del diseño. Barcelona, España: Paidós Ibérica.
Valenzuela, A. (1985, 14 de septiembre). La Junta edita un 'Manual de diseño' como orientación sobre sus servicios. El País Andalucía. Recuperado de https://elpais.com/diario/1985/09/14/ espana/495496821_850215.html [consultado en junio 2020].

Vergara Varela, J. P. (2016, 18 de octubre). Los escudos de Andalucía y la CNT. lavozdelsur.es. Recuperado de https://www.lavozdelsur.es/ los-escudos-de-andalucia-y-la-cnt/ [consultado en junio 2020]. 
